\title{
A Longitudinal Study on the Impact of Small-Sized Supporting Objects on Children Behavior
}

\author{
Linlin $\mathrm{He}^{1,2}$, Jinfu Zhang1,3, Xiaochun $\mathrm{Xu}^{4}$ \\ ${ }^{1}$ Center for Studies of Education and Psychology of Ethnic Minorities, Southwest University, Chongqing, China \\ ${ }^{2}$ School of Law, Southwest University of Science and Technology, Mianyang, China \\ ${ }^{3}$ School of Psychology, Southwest University, Chongqing, China \\ ${ }^{4}$ Affiliated Kindergarten, Southwest University of Science and Technology, Mianyang, China \\ Email: zhangif@swu.edu.cn
}

Received 8 April 2015; accepted 11 May 2015; published 12 May 2015

Copyright () 2015 by authors and Scientific Research Publishing Inc.

This work is licensed under the Creative Commons Attribution International License (CC BY).

http://creativecommons.org/licenses/by/4.0/

(c) (1) Open Access

\begin{abstract}
In this study, a preliminary test on 22 Chinese children was conducted. After 11 months, 11 children were successfully re-tested. The results indicated that, whether in body task or object task, children made more scale errors and acts of refusal without reason in the pre-test. Compared with the pre-test, children in the post-test were fully aware of the size of supporting objects, were more likely to refuse with reason, and made active pretending behaviors.
\end{abstract}

\section{Keywords}

Children, Scale Error, Pretend, Supporting Object, Target Object

\section{Introduction}

DeLoache et al. (2004) firstly pointed out in their study report that children often made mistakes in processing the visual information about the scale and size of some familiar items (DeLoache, Uttal, \& Rosengren, 2004). They found this phenomenon through informal observation in the laboratory and home. DeLoache et al. (2004) defined scale error as the phenomenon that infants and children made mistakes in processing the physical scale of objects, and persistently made efforts to complete some impossible actions on some small objects. DeLoache et al. (2004) pointed out that the scale error was characterized by children's multiple attempts to try to do some actions, with their sustained efforts and perseverance in the process of trying. For example, children try to get themselves into miniature toy cars, or constantly attempt to slide down from the palm-sized slide. 


\subsection{Classification of Scale Error}

Researchers usually divide scale errors into three categories: 1) Body scale errors, which mean that children try to get into some object that does not match with the size of children's body; 2) Object scale errors, which means that children try to inset one object into another object which does not match with it in size; 3) Functional scale errors, which are made by children who only consider the function of tool, but pay no attention to the size matching (DeLoache et al., 2004; Casler, Eshleman, Greene, \& Terziyan, 2011).

\subsection{Frequency Differences between Body Scale Error and Object Scale Error}

Ware, Uttal, Wetter, \& DeLoache (2006) found that children in the research of DeLoache (2004) made more object scale errors than body scale errors. The research results of Rosengren, Schein, \& Gutiérrez (2010) support this view. However, other studies yielded contradictory results (Brownell, Zerwas, \& Ramani, 2007; Rosengren, Gutiérrez, Anderson, \& Schein, 2009b). Brownell et al. (2007) found that the frequency of body scale error was more than the frequency of object scale error. The frequency of body scale error begins to decrease when children are at the age of 2 years old. Researchers believe that this change reflects the development characteristic that children begin to be aware of their own perception and characterization. Rosengren et al. (2009b) found through parents' reports that scale errors gradually decreased from toddlers to preschool-age children, the frequency of body scale errors was generally 4 times as the frequency of object scale errors, and that the occurrence rate of these two types of scale errors had no correlation. DeLoache et al. (2013) found that children often used the reason of "I am too big" to refuse the experimenter's invitation of asking them to pretend to enter the miniature toys. It can be seen that children clearly understand the relationship between their own body size and the size of target object. This also indicates that they are more concerned about themselves. Children who are more aware of their own body tend to make fewer scale errors than other children of the same age. Therefore, immature body self-awareness is one of the main causes for scale errors.

\subsection{The Frequency Change of Scale Error}

Some researchers believe that scale errors are gradually reduced when children grow up. DeLoache et al. (2004) observed 54 children aged at $18-30$ months in laboratory and found that the occurrence rate of scale error in 2year-old children was the highest, and then the occurrence rate decreased with age. The research of DeLoache et al. (2013) also got similar results. Some researchers believe that both body scale errors and object scale errors gradually decrease with age (Rosengren et al., 2009a; Rosengren et al., 2009b; DeLoache et al., 2004; Brownell et al., 2007). Brownell et al. (2007) observed 57 children aged at $18-26$ months in the laboratory, and found that most children made two kinds of scale errors, $90 \%-100 \%$ of participants made body scale errors, $42 \%-82 \%$ of participants made object scale errors, and the two kinds of scale errors were reduced with the increase of children's age. In the research of Rosengren et al. (2009b), parents observed children's behavior for six months and made a report. The research found that all the children aged between 3 months and 27 months, except 1 child, made more than one scale error; at the same time, the occurrence rate of scale error gradually decreased with age. Ware, Uttal, \& DeLoache (2010) investigated parents via the network and found that the frequency of scale errors that children made at home was similar to the result in the laboratory, that was, the occurrence rate of scale error gradually decreased before the end of the toddler period.

However, some research results indicated that the occurrence rate of object scale errors increased with the increase of children's age. Ware et al. (2006) considered that object scale errors increased with the increase of age. They adopted the experimental paradigm in DeLoache et al. (2004) and observed children aged at 16 - 40 months. They found that each child made 1.4 times of object scale error on average, while older children aged at 35 - 40 months made less object scale errors than the younger children aged at $16-24$ months. In the study, older children spent twice as much time on toys as younger children did. They believe that this difference is caused by children's using frequency and interest in the dolls and relevant toys used in the study. Older children may be more interested in dolls, and much more involved in the doll game, so they are more likely to make object scale errors. Rosengren, Schein, \& Gutiérrez (2010) also found similar findings by observing children in the kindergarten, that was, older children were more inclined to make object scale error.

The purpose of this experiment is to investigate Chinese children's awareness of the size of supporting objects, and check whether their behavior and scale errors under the condition of small-size objects will change with the increase of children's age. 


\section{Method}

\subsection{Participants}

The pre-test has a total of 22 qualified subjects, including 16 girls and 6 boys. They are divided into four age groups: 21 months (including 2 boys and 3 girls, the average age of the 5 children is 21.2 months), 26 months (including 5 girls, the average age of the 5 girls is 26.2 months), 32 months (including 6 girls and 1 boy, the average age of the 7 children is 32.6 months), 40 months (including 2 girls and 3 boys, the average age of the 5 children is 40.4 months). In the posttest, there are 11 qualified subjects, who made scale errors in the pre-test or refused to cooperate because of their awareness of the size of objects. Among them, the youngest child is 35 months old, the oldest child is 45 months old. The average age of all the subjects is 40 months old. All the subjects were recruited on a voluntary basis, subjects' parents are teaching staff of a university in Mianyang City. When participating in the experiment, all the qualified subjects' physical health, response level and emotional state were normal.

\subsection{Materials}

Standard toys (slide, chair, car), model toys (miniature slide, miniature chair, miniature car, which are about 8 $14 \mathrm{~cm}$ long), doll's clothes (Jacket, pants, shoes, hat, which is about $5 \mathrm{~cm}$ long), toys (bed, bathtub) which are in proportion with doll, miniature toys (small bed, bathtub, which is about $5-10 \mathrm{~cm}$ long).

The experimental paradigm is improved on the basis of Brownell, Zerwas, \& Ramani (2007) and DeLoache et al. (2013).

\subsection{Procedure}

This study is a longitudinal study, the time interval between pre-test and post-test is 11 months, and the experiment type is individual test.

The experiment tasks are divided into two parts: body task and object task. Both body task and object task include two subtasks, which are "playing with toys" and "putting on clothes". In order to avoid the influence of replacing experimental materials on children's test results, different tasks should be carried out in different rooms.

\subsection{Instruments}

- Body Toy Task

The first room is equipped with three standard-sized toys: slide, chair and toy car. The experimenter encourages children to sit on the chair, slide down from the slide and get into the toy car. Each child plays with each toy for about 5 minutes. Then children are brought to the second room to complete the task. The second room has miniature toys which have the same appearance with those in the first room: the slide is about $8 \mathrm{~cm}$ tall, the chair is about $6 \mathrm{~cm}$ tall, and the miniature car is about $6 \mathrm{~cm}$ long. The experimenter guides children to play with miniature toys for about 5 minutes (parents are required not to discuss the size of toy model). If children do not play with toys, the experimenter would guide children to do the corresponding task, for example: This is your chair, please sit on your chair! This is your slide, please slide down from the slide! This is your car, please get into the car and drive it!

- Body Dressing Task

In this task, the experimenter gives children small sized clothes, and guide children to play with these clothes for about 5 minutes (parents are required not to discuss the size of clothes). If a child does not act accordingly, the experimenter will guide the child to do the corresponding task, for example: This is your hat, please wear your hat! This is your jacket, please wear your jacket! These are your pants, please wear your pants! These are your shoes, please wear your shoes!

- Object Dressing Task

In this task, the experimenter requires children to put small-sized clothes on their parents, and needs parents' cooperation (parents are not allowed to talk about the size of clothes or whether they are appropriate). If a child does not act accordingly, the experimenter would guide the child to do the corresponding task, for example: This is your mother's (or...) hat, please put it on her head! This is your mother's (or...) jacket, please help her wear 
the jacket! These are your mother's (or...) pants, please help her wear the pants! These are your mother's (or...) shoes, please help her wear the shoes!

- Object Toy Task

In the first room, there are two 30m-tall dolls (one male doll and one female doll), a bed (with length of $80 \mathrm{~cm}$ long and width of $40 \mathrm{~cm}$ ) and a bathtub (with length of $100 \mathrm{~cm}$ and width of $60 \mathrm{~cm}$ ) which are in proportion with the doll. Each child is allowed to choose a doll, and then complete the task of washing doll and put the doll on the bed. Later, the experimenter asks children to bring their doll to the second room. In the second room, there are a miniature bed and a miniature bathtub with the size of $5-10 \mathrm{~cm}$, which are very similar to those in the first room. Children are allowed to spontaneously play with doll and miniature toys (parents should not make any comment on the size of miniature toys). If the child does not play with toys after 1 minute, the experimenter would guide the child to pay attention to the toys. The doll needs to take a bath now, please put it in a bathtub! Now the doll needs to sleep, please put it on the bed, so that it can sleep!

\subsection{Coding Procedure}

Children's behaviors are classified and sorted out according to their specific performances in each subtask. There are eight kinds of behaviors: 1) Refusal, giving no reason; 2) Refusal, giving specific reason, such as "I'm too big, it is too small"...; 3) Simple action. The action is neither accurate nor rich in form, for example, they just stretch out their hands to reach the miniature car; 4) Obviously pretend behavior. For example, some children just say that they are pretending to slip or slide down, or they pretend to do the action after the experimenter's encourages; some children follow the experimenter's request and make pretending behavior; 5) Scale error. Continuously make efforts to complete the impossible task; 6) A series of procedure actions. These actions are very meticulous, and are carried out according to certain procedures. For example, when giving the doll a bath, children need to put the doll into the bathtub, then wash the doll's hair, body and hands...; 7) Perception of the object's size after performing tasks. Some children directly do the impossible task according to the requirements of experimenter, they are not aware of the size problem until they find that they cannot complete the task. For example, some children sat on the miniature chair, then smiled and said: "No, it's too small"; 8) Other playground behavior. For example, some children put the car on the slippery slide, play with the clothes by putting them on their head, or take the miniature chair and run around the room.

If the child's behavior is in line with the characteristic of a certain type of behavior, 1 point will be recorded for the type of behavior, then 0 point will be recorded in the other seven behavior types.

\section{Results}

\subsection{Differences in Children's Behaviors in Performing Body Tasks between Pre-Test and Post-Test}

In order to investigate whether there are differences in children's behaviors in performing the 7 body tasks, which include slide, chair, miniature car, jacket, pants, hat and shoes, between pre-test and post-test, a comparative analysis on the frequency of children's behaviors in performing each task is carried out. Chi-square test results indicate that children's behaviors in performing the body tasks in pre-test differ greatly from those in posttest, $\chi^{2}=69.295, p=0.000<0.001$.

As shown in Table 1, it can be seen in the body tasks of pre-test: There is an equal number of children who give the specific reason for refusal and the children who make scale errors; Children also have many behaviors of refusal without reason. The second are simple action and perception the object's size after action. There is no child to take the initiative to perform pretend behavior. In the pre-test body tasks: The number of children who refusing with reason ranks first, followed by the number of children who do pretend behavior, only $5.2 \%$ of children begin to realize the size problem after taking actions, and only $3.9 \%$ of children make scale error.

To further investigate whether children have different responses when performing the body tasks (slide, chair, car) and body dressing tasks (jacket, pants, hat, shoes) in the pre-test and post-test, a comparative analysis on the frequency of children's behaviors in performing each task is carried out. Firstly, the frequency of children's behaviors in body tasks of mini slide, chair and car is studied and analyzed. The chi-square test results indicate that there are very significant differences in children's behaviors in pretest and posttest, $\chi^{2}=24.882, p=0.000<$ 0.001 . 
As shown in Table 2, it can be seen in the post-test: There is no child commit those actions such as refusal without reason, simple actions, perception the object's size after action and other game actions; but these behaviors all appear in the pre-test. In the post-test, the majority can refuse with the reason, followed by obvious pretend behavior committed by children. There are $9.1 \%$ of children still made scale errors. It can be seen from comparison that most children are clearly aware of the object's size and be able to refuse with reason when performing the toy body tasks. There are also many obvious pretend actions, and the phenomenon of scale error is significantly lower than the pre-test.

Then, a comparative analysis on the frequency of children's behaviors in body toy tasks such as the jacket, pants, hat and shoes is carried out. Chi-square test results indicate that there are very significant differences in children's behaviors in performing each body task between pre-test and post-test, $\chi^{2}=47.521, p=0.000<$ 0.001 .

As shown in Table 3, it can be seen that when children were performing the body dressing task in pre-test: Most children make scale errors, followed by the number of children who refusal with reason, and the number of children who could not refuse with reason for ranks the third, accounting for $20.5 \%$; The number of children who did not realize the size problem until performing actions ranks the forth. However, in the post-test, most children can give a reason for rejection, the number of children who make obvious pretense ranks the second, and there were only a few children who did not realize the size problem until they do actions. No children made scale errors or other game behaviors in the post-test.

\subsection{Differences in Children's Behaviors in Performing Object Tasks in Pre-Test and Post-Test}

In order to investigate whether there are differences in children's behaviors in performing the 6 object tasks, which include bath, sleep, jacket, pants, hat and shoes, in pre-test and post-test. A comparative analysis on the frequency of children's behaviors in performing each task is carried out. Chi-square test results indicate that children's behaviors in performing the body tasks in pre-test differ greatly from those in post-test, $\chi^{2}=65.610, p$ $=0.000<0.001$.

Table 1. Children's behaviors in performing the body tasks in pre-test and post-test (frequency/percentage).

\begin{tabular}{|c|c|c|c|}
\hline Behavior type & Pre-test & Post-test & Total \\
\hline Refusal without reason & $16(0.8 \%)$ & $0(0.0 \%)$ & $16(10.4 \%)$ \\
\hline Refusal with reason & $24(31.2 \%)$ & $49(63.6 \%)$ & $73(47.4 \%)$ \\
\hline Simple action & $6(7.8 \%)$ & $0(0.0 \%)$ & $6(3.9 \%)$ \\
\hline Obviously pretend & $0(0.0 \%)$ & $21(27.3 \%)$ & $21(13.6 \%)$ \\
\hline Scale error & $24(31.2 \%)$ & $3(3.9 \%)$ & $27(17.5 \%)$ \\
\hline Perception size after action & $6(7.8 \%)$ & $4(5.2 \%)$ & $10(6.5 \%)$ \\
\hline Other playground behavior & $1(1.3 \%)$ & $0(0.0 \%)$ & $1(0.6 \%)$ \\
\hline
\end{tabular}

Table 2. Children's behaviors in performing the toy body tasks in pre-test and post-test.

\begin{tabular}{|c|c|c|c|}
\hline Behavior type & Pre-test & Post-test & Total \\
\hline Refusal without reason & $7(21.2 \%)$ & $0(0.0 \%)$ & $7(10.6 \%)$ \\
\hline Refusal with reason & $13(39.4 \%)$ & $21(63.6 \%)$ & $34(51.5 \%)$ \\
\hline Simple action & $2(6.1 \%)$ & $0(0.0 \%)$ & $2(3.0 \%)$ \\
\hline Obviously pretend & $0(0.0 \%)$ & $9(27.3 \%)$ & $9(13.6 \%)$ \\
\hline Scale error & $9(27.3 \%)$ & $3(9.1 \%)$ & $12(18.2 \%)$ \\
\hline Perception size after action & $1(3.0 \%)$ & $0(0.0 \%)$ & $1(1.5 \%)$ \\
\hline Other playground behavior & $1(3.0 \%)$ & $0(0.0 \%)$ & $1(1.5 \%)$ \\
\hline
\end{tabular}


It can be seen from this experiment that in the object tasks of pre-test: The most frequent behavior is scale error $(40.9 \%)$, followed by refusal without specific reason $(24.2 \%)$, the refusal with reason $(21.2 \%)$ ranks the third, the number of children who did not realize the size problem until they do actions ranks the fourth $(7.6 \%)$, then followed by simple action (4.5\%) and a series of procedure actions (1.5\%). However, in the object tasks of post-test: The most frequent behavior is refusal with specific reason $(69.7 \%)$, followed by simple action $(18.2 \%)$, awareness of size problem after doing actions (7.6\%), and very few obvious pretending behavior (3.0\%) and scale errors (1.5\%). This indicates that children have significant differences in the performance of different tasks. In post-test, children tend to refuse with specific reason. In pre-test, children are more likely to make scale error.

To further investigate whether children have different responses when performing the object tasks (bath and sleep) and object dressing tasks (jacket, pants, hat and shoes) in the pre-test and post-test, comparative analysis on the frequency of children's behaviors in performing each task is carried out. Firstly, the frequency of children's behaviors in performing bath and sleep object tasks is compared. The chi-square test results indicate that there are very significant differences in children's behaviors in performing these subtasks between pre-test and post-test, $\chi^{2}=18.098, p=0.006<0.01$.

As shown in Table 4, it can be seen that the proportion of scale error ranks the first in the object toy tasks of pre-test, but it only accounts for $4.5 \%$ in the post-test. In the posttest, most children can give a reason for refusal, the number of children who cannot do give specific reason for refusal is reduced to be 0 , and the number of children who are not aware of size problem until taking actions is also reduced.

Then, a comparative analysis on the frequency of children's behaviors in object dressing tasks such as the jacket, pants, hat and shoes is carried out. The chi-square test results indicate that there are very significant differences in children's behaviors in performing each subtask between pre-test and post-test, $\chi^{2}=52.190, p=$ $0.000<0.001$.

As shown in Table 5, it can be seen that children were performing the object dressing tasks of pre-test, most children tend to make scale errors, the number of children who refuse without reason and refuse with reason rank the second. However, in the post-test, most children tend are able to give clear reason for refusal and make simple actions.

\subsection{Changes in the Type of Children's Behaviors in Pre-Test and Post-Test}

As shown in Table 6, it can be seen that children who couldn't give specific reason for refusal, or made scale

Table 3. Children's behaviors in performing the body dressing task in pre-test and post-test.

\begin{tabular}{cccc}
\hline Behavior type & Pre-test & Post-test & Total \\
\hline Refusal without reason & $9(20.5 \%)$ & $0(0.0 \%)$ & $9(10.2 \%)$ \\
Refusal with reason & $11(25.0 \%)$ & $28(63.6 \%)$ & $39(44.3 \%)$ \\
Simple action & $4(9.1 \%)$ & $0(0.0 \%)$ & $4(4.5 \%)$ \\
Obviously pretend & $0(0.0 \%)$ & $12(27.3 \%)$ & $12(13.6 \%)$ \\
Scale error & $15(34.1 \%)$ & $0(0.0 \%)$ & $15(17.0 \%)$ \\
Perception size after action & $5(11.4 \%)$ & $4(9.1 \%)$ & $9(10.2 \%)$ \\
\hline
\end{tabular}

Table 4. Children's behaviors in performing the object toy task in pre-test and post-test.

\begin{tabular}{|c|c|c|c|}
\hline Behavior type & Pre-test & Post-test & Total \\
\hline Refusal without reason & $2(9.1 \%)$ & $0(0.0 \%)$ & $2(4.5 \%)$ \\
\hline Refusal with reason & $4(18.2 \%)$ & $14(63.6 \%)$ & $18(40.9 \%)$ \\
\hline Simple action & $3(13.6 \%)$ & $4(18.2 \%)$ & $7(15.9 \%)$ \\
\hline Obviously pretend & $0(0.0 \%)$ & $2(9.1 \%)$ & $2(4.5 \%)$ \\
\hline Scale error & $9(40.9 \%)$ & $1(4.5 \%)$ & $10(22.7 \%)$ \\
\hline Perception size after action & $3(13.6 \%)$ & $1(4.5 \%)$ & $4(9.1 \%)$ \\
\hline
\end{tabular}


Table 5. Children's behaviors in performing the object dressing task in pre-test and post-test.

\begin{tabular}{cccc}
\hline Behavior type & Pre-test & Post-test & Total \\
\hline Refusal without reason & $14(31.8 \%)$ & $0(0.0 \%)$ & $14(15.9 \%)$ \\
Refusal with reason & $10(22.7 \%)$ & $32(72.7 \%)$ & $42(47.7 \%)$ \\
Simple action & $0(0.0 \%)$ & $8(18.2 \%)$ & $8(9.1 \%)$ \\
Scale error & $18(40.9 \%)$ & $0(0.0 \%)$ & $18(20.5 \%)$ \\
Perception size after action & $2(4.5 \%)$ & $4(9.1 \%)$ & $6(6.8 \%)$ \\
\hline
\end{tabular}

errors, or began to be aware of the size problem after trial in the pre-test, tend to give a specific reason for refusal in the post-test. Among the children who made scale errors in the pre-test, $40.00 \%$ of them gave clear refusal in the post-test, and $26.00 \%$ of them had obvious pretending behavior, $16.00 \%$ of them showed simple action, $12.00 \%$ became aware of size problem after performing the actions, only $6.00 \%$ of them still made scale errors (Table 6).

\section{Discussion}

When performing body tasks, children in this experiment tend to be able to give the reason for refusal or make scale errors; the occurrence rate of these two kinds of behaviors is the same. In addition, many children refuse to perform the task, but cannot give a specific reason. Followed by simple action and awareness of size problem after taking actions, no children take the initiative to make pretending behavior. However, in the post-test, no children refuse to perform the task without giving a specific reason. Most children can give a specific reason for refusal, and the number of children who make obvious pretending behaviors ranks the second. In the post-test of performing toy body tasks, most children are aware of the size problem, and speak out the reason for refusal. There are more pretending behaviors in the post-test; the scale errors are reduced significantly when compared with pre-test. In the post-test of body dressing task, the most frequent behavior is refusing and giving specific reason for refusal, then is the obvious pretending behavior; the rarest behavior is awareness of size problem after taking actions; children make no scale error or other type of behavior. Obviously, with the increase of age, more and more children become aware of the size of supporting objects. When experimenter asks them to complete tasks, they can clearly tell the experimenter that they cannot complete the task because of size problem.

When performing body tasks in the pre-test, the most frequent behavior is scale error, followed by refusal without a specific reason, the refusal with reason ranks the third, the number of children who do not realize the size problem until they take actions ranks the fourth, and then followed by simple action and a series of procedure actions. However, when performing in the object tasks of post-test, the most frequent behavior is refusal with specific reason, followed by simple action, awareness of size problem after taking actions, and very few obvious pretend behavior and scale error. This indicates that children have significant differences in the performance of different tasks. In post-test, children tend to refuse with specific reason. In the object toy tasks, children are more likely to make scale errors in the pre-test, and they tend to specify the reason for refusal in the post-test. In the task object clothes, when children are performing the object dressing tasks in the pre-test, most children tend to make scale errors, and the number of children who give reason for refusal and the number of children who can give reason for refusal rank the second. However, in the post-test, most children tend to be able to give a clear reason for refusal and make simple actions. With the increase of age, children gradually become aware of the scale errors of supporting objects, and are more likely to be able to point out the reason for refusal, and make active pretending behaviors.

It can be seen that no matter in body task or object task, regardless of toy task or dressing task, children are more likely to make scale errors in the pre-test. In this study, the proportion of scale error in pre-test of body task is $31.2 \%$, and the proportion of scale error in pre-test of object task is $40.9 \%$. Meanwhile, the proportion of scale error in the post-test of body task is 3\%, and the proportion of scale error in the post-test of object task is $1 \%$. This is consistent with the research results of Brownell et al. (2007), who find that scale error decreases with age; it is more difficult for children to check whether they are obstacles than to find the characterization of objective objects; the scale error occurs because it is difficult for children to treat their body as an objective entity; when children have better understanding of their own bodies, they will make fewer scale errors. 
Table 6. Changes in children's behaviors in pre-test and post-test (percentage).

\begin{tabular}{cccccccccccc}
\hline $\begin{array}{c}\text { Pre-test } \\
\text { Post-test }\end{array}$ & 1 & 2 & 3 & 4 & 5 & 6 & 7 & 8 & Total \\
\hline 1 & $3.13 \%$ & $96.88 \%$ & 0 & 0 & 0 & 0 & 0 & 0 & $100 \%$ \\
2 & 0 & $26.32 \%$ & 0 & $73.68 \%$ & 0 & 0 & 0 & 0 & $100 \%$ \\
3 & 0 & $11.11 \%$ & 0 & 0 & 0 & 0 & $88.89 \%$ & 0 & $100 \%$ \\
4 & 0 & 0 & 0 & 0 & 0 & 0 & $100.00 \%$ & 0 & $100 \%$ \\
5 & 0 & $40.00 \%$ & $16.00 \%$ & $26.00 \%$ & $6.00 \%$ & 0 & $12.00 \%$ & 0 & $100 \%$ \\
6 & 0 & $100.00 \%$ & 0 & 0 & 0 & 0 & 0 & 0 & $100 \%$ \\
7 & 0 & $54.55 \%$ & $27.27 \%$ & 0 & $9.09 \%$ & 0 & $9.09 \%$ & 0 & $100 \%$ \\
8 & 0 & $100.00 \%$ & 0 & 0 & 0 & 0 & 0 & 0 & $100 \%$ \\
\hline
\end{tabular}

Note: 1. Refusal, giving no reason; 2. Refusal, giving specific reason; 3. Simple action; 4. Obvious pretend behavior; 5 . Scale errors; 6 . A series of procedure actions; 7. Awareness of the size problem after performing the action; 8 . Other playground behavior. Similarly hereinafter.

As can be seen from the above-mentioned results, in the pre-test phase, no child makes pretending behavior under the guidance of the experimenter. It can be seen from the analysis of post-test data that in addition to the object dressing task, children also make pretending behavior in other three tasks. The obvious and active pretending behavior frequently appears in the body toy and body dressing tasks. It is found in the post-test experiment that many students can actively use pretending behavior to solve the conflicts and contradictions between experimenter's requirements and the size of supporting objects. There were two children who used simple symbolic actions when experimenter asked them to complete the task: they smiled and told the experimenter, "I am pretending!" Obviously, with the increase of age, children gradually become aware of the size problem of supporting objects and the impact of size on implementation of action. Meanwhile, when children encounter the conflict between the size of supporting object and the target behavior, but have to perform the task, most of them consider pretending behavior as a good way to solve this thorny issue. For these children, they can ignore the size of supporting objects when making pretending behavior; because this is just a hypothesis, it is not true. In contrast, children tend to make more pretending behaviors in the context of body tasks. Therefore, we speculate that when performing body tasks, children need to complete certain tasks by themselves; once they fail to complete the task, they may find fault from themselves; so, they have more motivation to find a solution. However, in the object tasks, children are more likely to attribute the failure to object, and so many children just report that the task cannot be completed because of size problem, or use simple actions to deal with the situation in posttest. Children's simple action may be a response to the experimenter's command, or a flexible action of children when they cannot truly complete the task. We can see from the experiment that some children pretend to complete the task with imagination; they act on a small scale, and say "I have entered it, or I have washed it". So, we infer that these simple actions may also include some pretending actions that some children are not aware of, or they cannot describe in language. Meanwhile, we guess that the scene may be also an important factor affecting children's pretend behavior.

\section{Result}

- Children are more likely to make scale errors in the pre-test. Children's scale errors are reduced significantly with age.

- More and more children become aware of the size of supporting objects with the increase of age. Children tend to refuse with reason in the post-test.

\section{Acknowledgements}

This study is funded by Early Development and Education Research Center for children aged at 0 - 3 years old in Sichuan Province of China (SCLS14-024).

\section{References}

Brownell, C. A., Zerwas, S., \& Ramani, G. B. (2007). "So Big": The Development of Body Self-Awareness in Toddlers. 
Child Development, 78, 1426-1440. http://dx.doi.org/10.1111/j.1467-8624.2007.01075.x

Casler, K., Eshleman, A., Greene, K., \& Terziyan, T. (2011). Children's Scale Errors with Tools. Developmental Psychology, 47, 857. http://dx.doi.org/10.1037/a0021174

DeLoache, J. S., LoBue, V., Vanderborght, M., \& Chiong, C. (2013). On the Validity and Robustness of the Scale Error Phenomenon in Early Childhood. Infant Behavior and Development, 36, 63-70. http://dx.doi.org/10.1016/j.infbeh.2012.10.007

DeLoache, J. S., Uttal, D. H., \& Rosengren, K. S. (2004). Scale Errors Offer Evidence for a Perception-Action Dissociation Early in Life. Science, 304, 1027-1029. http://dx.doi.org/10.1126/science.1093567

Rosengren, K. S., Carmichael, C., Schein, S. S., Anderson, K. N., \& Gutiérrez, I. T. (2009a). A Method for Eliciting Scale Errors in Preschool Classrooms. Infant Behavior and Development, 32, 286-290. http://dx.doi.org/10.1016/j.infbeh.2009.03.001

Rosengren, K. S., Gutiérrez, I. T., Anderson, K. N., \& Schein, S. S. (2009b). Parental Reports of Children's Scale Errors in Everyday Life. Child Development, 80, 1586-1591. http://dx.doi.org/10.1111/j.1467-8624.2009.01355.x

Rosengren, K. S., Schein, S. S., \& Gutiérrez, I. T. (2010). Individual Differences in Children's Production of Scale Errors. Infant Behavior and Development, 33, 309-313. http://dx.doi.org/10.1016/j.infbeh.2010.03.011

Ware, E. A., Uttal, D. H., \& DeLoache, J. S. (2010). Everyday Scale Errors. Developmental Science, 13, 28-36. http://dx.doi.org/10.1111/j.1467-7687.2009.00853.x

Ware, E. A., Uttal, D. H., Wetter, E. K., \& DeLoache, J. S. (2006). Young Children Make Scale Errors When Playing with Dolls. Developmental Science, 9, 40-45. http://dx.doi.org/10.1111/j.1467-7687.2005.00461.x 